\title{
Study on Online Shopping Rights Protection from Perspective of Impairment of Online Shopping Rights and Interests of College Students
}

\author{
Cuifen Huang \\ Yunnan Technology and Business University, Kunming, 651700, China
}

\begin{abstract}
Keywords: Online shopping infringement, College students, Online shopping rights protection;
\end{abstract} After-sales service, Cost of violation of laws, Rights protection cost

\begin{abstract}
With the popularization of internet information society and the rapid development of logistics service industry, online shopping has become one of the most important consumption patterns of Chinese consumers. In particular, the convenience and diversity of online shopping are attractive to younger generations such as college students. With the gradual enrichment of online shopping function of mobile terminal, they become main consumers of Chinese e-commerce online shopping platform. However, online shopping is not an optimal harmless consumption pattern. The impairment of online shopping rights and interests of college students caused by various problems in law and consumers' weak awareness of rights and interests protection has occurred frequently in recent years, which not only damages college students' vital interests, but also hinders the development of online shopping transactional model and damages the normal buyer-seller relationship. This paper first reveals data of field investigation on online shopping consumers of college students, points out subjective and objective reasons for the impairment of online shopping rights and interests of college students and discusses the specific countermeasures for online shopping rights protection from this perspective.
\end{abstract}

\section{Introduction}

According to data of Chinese online shopping market in 2014, the transaction scale of domestic online shopping market has risen to 3.1 trillion Yuan with a growth rate of up to $48.8 \%$.With the popularization of intelligent mobile terminal, it is expected that the proportion of online shopping of Chinese online shopping consumers with intelligent mobile terminal will exceed that with home PC, which will become the first choice of Chinese netizens in online shopping. As described above, various advantages of online shopping such as convenience, rapidness and cheapness have attracted most domestic consumers, among which college students account for $63.8 \%$ and are absolute main forces of Chinese online shoppers. However, as young students not entering the society, college students have many natural disadvantages in online shopping. Due to weak legal consciousness of Chinese citizens and serious inadequacy of protection of their rights and interests, online shopping infringement becomes a regular obstacle, which influences the relationship between consumers and merchants seriously and is adverse to the long-term healthy development of Chinese e-commerce platform in the future.

\section{Field investigation and analysis on college students in colleges and universities in a region}

To know the status of online shopping of college students, 600 college students in 3 colleges and universities in a region were investigated. Among them, those basically relying on online shopping except daily meals account for $4.6 \%$, those often buying daily consumables and other products on the internet account for $37.8 \%$, those shopping on the internet occasionally account for $48.6 \%$, those rarely shopping on the internet account for $8 \%$ and those never shopping on the internet only account for $1 \%$.These data indicate that online shopping has basically become a common and essential lifestyle of domestic college students.

According to further investigation, among college students often shopping on the internet, those buying clothes and books \& DVDs electronic products respectively account for $45.8 \%$ and $28.9 \%$, followed by those buying food (17.4\%). The rest 7.2\% students buy cosmetics or other articles. 
In terms of infringement of online shopping rights and interests, over $70 \%$ college students admitted that they suffered from the damage of rights and interests. Reasons in the first three places include product quality, logistics distribution and difficulty in return and exchange of goods. Product quality problem even hold over a half proportion. Therefore, the most prominent problem is product quality of online shopping in terms of damage of college students' online shopping rights and interests. When suffering from infringement of rights and interests, $64 \%$ college students chose to contact with the merchant for negotiation and rights protection and ask for return, exchange or repair of goods, $21 \%$ college students gave a negative comment; only $15 \%$ college students made a complaint to online customer service staff and consumers' association and no one asked for remedy through legal action and social efforts.

The whole investigation involves online shopping habits of college students and tendency of online shopping objects as well as reactions and countermeasures after the damage of rights and interests. Though the whole investigation only involves 600 college students, it can represent the common mental state of college students in online shopping to a certain extent, i.e. most college students have nowhere to protect their rights and interests or choose to give up rights protection when suffering from the damage of rights and interests. This is adverse to the formation of safe and pure environment of domestic online shopping platform. Therefore, this paper analyzes subjective and objective factors of the difficulty in online shopping rights protection based on laws and college students' psychology and attempts to make suggestions on the solution.

\section{Analysis on subjective and objective factors of difficulty in online shopping rights protection}

\section{Analysis on objective factors.}

Objective factors of the difficulty in online shopping rights protection of college students are mainly from legal level. As is known to all, most college students in China have relatively weak legal consciousness. This is the short slab of Chinese higher education. In particular, even most highly educated college students are unqualified in the learning and mastery of consumer law. It is a common problem of Chinese citizens. Business parties cannot abide by legal norm well with such weak consciousness of right which breaks normal consuming behavior. Therefore, it is obvious that the difficulty in online rights protection is manifested between consumers and merchants.

First, infringement act is illegal. Article 55 of new Law on Protection of Rights and Interests of Consumers in China stipulates, "Operators having any fraudulent conduct in the provision of goods or services shall add compensation for losses of consumers according to their requirements and the added amount of compensation shall be triple of the price of goods purchased or services received by consumers."Costs of violation of laws should include external costs and private costs of violation of laws according to differences of undertakers. External costs of violation of laws are mainly undertaken by the state and the society jointly in China. External costs incurred by infringement act of merchants are undertaken by consumers and social economic order jointly and merchants undertake private costs of violation of laws. From the perspective of merchants, private costs of violation of laws are generally low even when rights and interests of consumers are protected in some cases. However, if merchants' unlawful act is not punished, its low cost will produce high profits. Not all consumers will not get a reasonable and legal rights protection result. However, once rights and interests of any consumer are not protected, merchants will get extravagant profits. This also fosters their confidence in continuing to implement infringement act. When college student consumers do not know the amount and way of compensation after infringement, their interests are impaired and then social economic order is damaged indirectly. Losses incurred by such impairment are external costs of violation of law to be undertaken by the society and cannot be made up for through compensation for damages.

\section{Analysis on subjective factors.}

An subjective factor of the difficulty in online shopping rights protection of college students is high costs of rights protection. According to the current situation, high illegal profits of merchants and high costs of rights protection of college students indicate a situation of imbalance between buyers and sellers caused by the inadequacy of legal norm. This makes many college students hold a 
negative attitude when suffering from the infringement of rights and interests. This paper takes punitive indemnity clause in article 44 of new Law on Protection of Rights and Interests of Consumers for example. If the cost of consumers in rights protection act in $\mathrm{B}$ and the benefit obtained through rights protection is $\mathrm{C}$ and $\mathrm{C}-\mathrm{B}>0$ under the state without considering any other factor, it is possible for consumers to conduct rights protection against infringement act. If the clause that triple losses should be compensated for infringement act required in the new Law on Protection of Rights and Interests of Consumers is used as the standard, $C=B^{\prime}=3 B$. Consumers' cost $\mathrm{W}$ should be $\mathrm{W}<\mathrm{B}$ '. If other factors are considered, i.e. time spent by consumers on rights protection is $\mathrm{T}$, the value of $\mathrm{V}$ will be influenced by the change of $\mathrm{T}$ definitely. If various costs of consumers for rights protection are considered and expressed as $\mathrm{M}, \mathrm{W}=\mathrm{M} * \mathrm{~T}$. In real transactions, college students might not be able to persuade merchants with their own abilities or might meet various obstacles when encountering online shopping quality problem. At this time, money and time for various examinations on goods quality will be involved, which are far more than earnings brought by rights protection for college student consumers. Therefore, $\mathrm{M} * \mathrm{~T}>\mathrm{C}$. That is to say, college students will give up rights protection due to this subjective factor.

According to the inference above, high costs of rights protection make many college students attending online shopping activities give up rights protection subjectively. Though some college students have a strong awareness of rights protection, a group of data is revealed in this investigation, i.e. reasons for giving up the return or exchange of goods: $35.99 \%$ students think that some merchants should undertake the return freight; $26.13 \%$ students think that the product does not meet the value of expectation but its price is low; 22.79\% students think that the process of return or exchange of goods is too complicated and they might encounter the evasion of merchants; other students think that they cannot keep the bill properly, which will cause the failure of return of goods or warranty. Data above show another problem existing in Chinese online shopping transaction activities, i.e. high cost of rights protection and higher costs of after-sales service for consumers. This is a main subjective reason why many college student consumers of online shopping give up rights protection after the impairment of their rights and interests ${ }^{[2]}$.

\section{Study on countermeasures for online shopping rights protection of college students}

Considering the difficulty in online shopping rights protection of college students from legal to psychological level caused by subjective and objective factors above, this paper provides relevant countermeasures for rights protection in three aspects - law, college students and society.

\section{Legal aspect.}

First, electronic merchant access mechanism of online shopping platform should be controlled strictly. As network is virtual and open, the access mechanism of e-commerce platform is always low in China, which causes the failure to realize network market standardization. If the access mechanism of e-commerce platform can be improved, e.g. add the real information provided by electronic merchants during registration and even handle relevant certificates and make the information of electronic merchants completely open and transparent, college students and even all consumers can have a direct understanding of merchants before consumption. Therefore, the difficulty in rights protection of consumers will be reduced.

Second, it is required to establish a third-party online shopping rights protection platform, overcome defects in online shopping jurisdiction system, connect sellers and buyers harmoniously and maintain their respective due rights and interests jointly. The platform shall be constituted by relevant departments such as industry and commerce department and consumers' association which shall be responsible for coordinating transaction payment and after-sales service of consumers. Moreover, the third-party rights protection platform should release the information involving interests of parties in time, guarantee the transparency of transaction information, realize effective coordination of information transfer on the whole network and break the bottleneck mechanism of regional jurisdiction of online shopping in tradition. 


\section{Aspect of college student consumers.}

\section{Establish correct value}

First, college student consumers should deny any irresponsible online shopping transaction behavior of sellers and take corresponding actions. Meanwhile, college students should experience the difficulty of earning money in their life, i.e. establish a correct attitude towards money and value and build a stable line of defense for online shopping safety. Whenever suffering from the infringement of rights and interests, college students should be bold to protect their rights and interests as consumers, good at exposing fraudulent acts of online shopping and careful in the selection of online shopping objects. Such attitudes as "it is too troublesome" and "the price is low" should be eradicated as they indulge electronic merchants and might be adverse to other consumers.

Rational consumption

College students are mostly blind and irrational in online shopping. This accords with the consumption attitude of younger generations. Therefore, college students should establish a correct attitude towards consumption, treat online shopping as an emerging shopping pattern correctly, overcome blindness in purchasing psychology, make ends meet, realize rational, appropriate and green consumption and avoid being attracted by any low price and discount and be a qualified and smart consumer.

\section{Social aspect.}

Besides the third-party rights protection by law, small litigation system and online dispute resolution mechanism should be established for online shopping platform in social aspect. First, small litigation system is characterized by low amount, simple and high-efficiency registration. Its establishment can effectively solve problems of high cost and long time of rights protection of college students. For common people, it is an effective judicial form for remedying rights of small amount. Online dispute resolution mechanism completely conforms to the will of parties about free choice of consumption and resolves disputes through online negotiation via a neutral third party. It is flexible and efficient and has a low cost for problem solving. It is also a network rights protection method appropriate to college student consumers ${ }^{[3]}$.

\section{Conclusion}

It is the golden stage of online shopping development in China now. The attitude of people towards online shopping has changed from doubt to openness. Especially for college students, online shopping even becomes an important part in their life. Faced with the current fierce market economic competition and benefit dispute, college student consumers must enrich their awareness of rights protection by law and protect their legitimate rights and interests. Meanwhile, the society should establish a reasonable rights protection mechanism for consumers, help them reduce costs of rights protection, increase merchants' cost of violation of laws and prevent the re-occurrence of high profits with low costs of violation so that college students and even all online shopping consumers will not be harmed in online shopping consumption.

\section{References}

[1] Peng Jingya. Study on Impairment of Online Shopping Rights and Interests of College Students and Countermeasures. Legal System and Society, 2015(9):69-70.

[2] Shi Jingyi. Dilemma and Outlet of Online Shopping Rights Protection of College Students-- from Perspective of Law and Economics. Zhifu Era, 201,(4):33-34.

[3] Wu Zheting, Chen Yan. Study on Status and Problems of Online Shopping of College Students --Take Students in Colleges and Universities in Ningbo for Example. Consumption Guide, 2012(1):11-13. 